RESEARCH PAPER RP1224

Part of Journal of Research of the National Bureau of Standards, Volume 23, July 1939

\title{
STRENGTH OF A WELDED STEEL RIGID FRAME
}

\author{
By Ambrose H. Stang and Martin Greenspan
}

ABSTRACT

The distribution of stress in the knee of a welded steel rigid-frame specimen having straight flanges was determined from strain measurements. The maximum load also was determined.

\section{CONTENTS}

I. Introduction

II. Description of the specimen

III. Testing procedure

IV. Measured stresses....

V. Maximum load

VI. Summary

VII. References_....... 150

\section{INTRODUCTION}

With the cooperation of the American Institute of Steel Construction, tests have been made on three steel rigid-frame specimens.

The results on a riveted specimen having straight flanges have been reported in RP1130 [1], ${ }^{1}$ and on a riveted specimen having a curved inner flange in RP1161 [2]. The results on a welded specimen having straight flanges are reported here. This specimen was donated by Lukenweld, Inc.

\section{DESCRIPTION OF THE SPECIMEN}

The welded rigid-frame specimen is shown in figure 1 . It was fabricated from steel plates and bars joined by welding. The weight as determined by Lukenweld, Inc., was $2,030 \mathrm{lb}$. The specimen was approximately symmetrical about the diagonal stiffeners through the knee.

\section{TESTING PROCEDURE}

The rigid-frame specimen was tested in a vertical, screw-driven, beam-and-poise testing machine having a capacity of 600 kips. The load was not applied through pin-connected shoes as in previous tests $[1,2]$. The end flanges of the specimen were in direct contact with the platens of the testing machine.

Strain-gage readings were taken on 252 rosettes located as shown in figure 1 with Whittemore strain gages, 2-in. gage length. One division on the dial of the strain gage corresponds to a strain of 0.00005 . Readings were estimated to 0.1 division. Each rosette consisted of

\footnotetext{
${ }^{1}$ Figures in brackets indicate the literature references at the end of this paper.
} 
four gage lines intersecting at a point and inclined at $45^{\circ}$ to one another.

Each rosette location shown in figure 1 represents two rosettes, one on each side of the specimen.

The specimen in the testing machine is shown in figure 2. Before strain-gage readings were taken, a compressive load of 57 kips was applied and released five times. Strain-gage readings were taken at compressive loads of 4 kips and 54 kips.

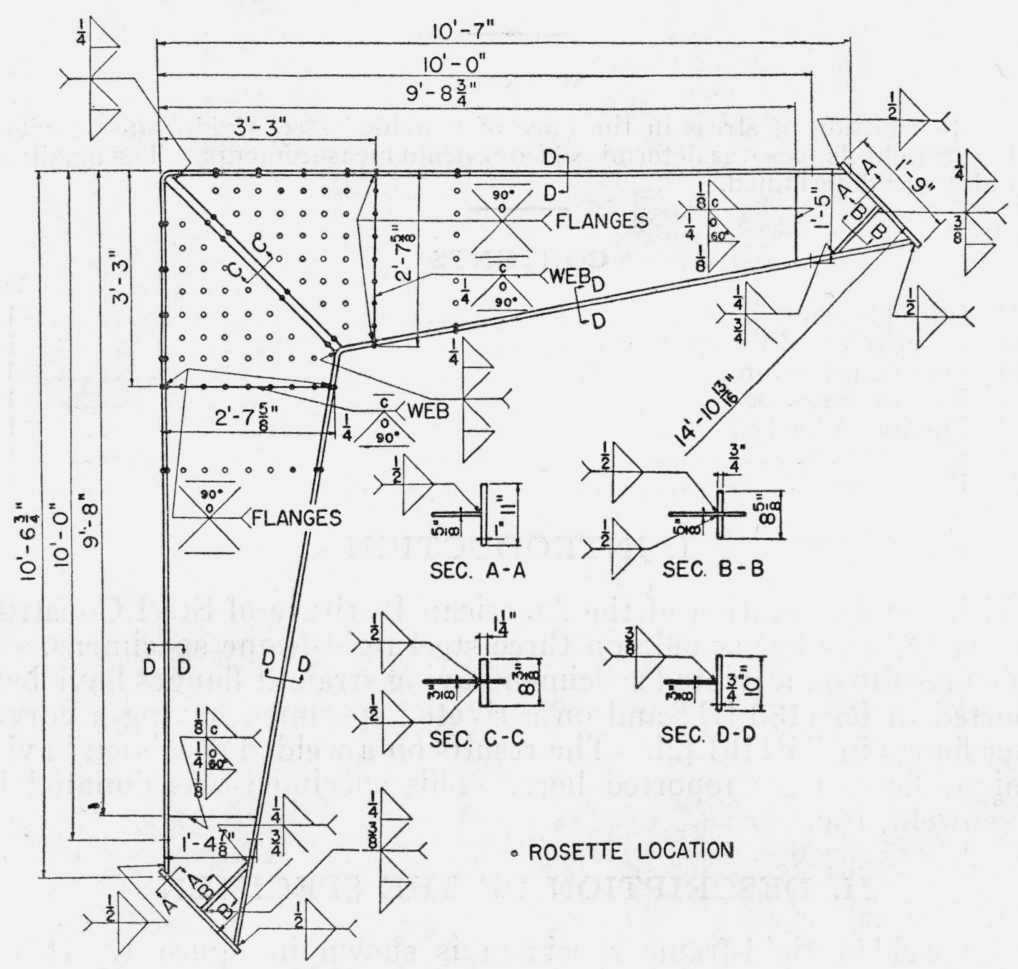

FiguRe 1.-Welded rigid-frame specimen.

The welding symbols are those of the American Welding Society [3].

\section{MEASURED STRESSES}

Stresses computed from the strain-gage readings will be called measured stresses. These stresses were computed from the strains due to the 50-kip increase in load by the methods outlined in RP1130 [1] using an assumed ${ }^{2}$ Young's modulus of elasticity of $29,000 \mathrm{kips} / \mathrm{in} .{ }^{2}$ For the web the strains in corresponding gage lines of rosettes on opposite sides were averaged and the average values used in the computations. For the flanges the strains in corresponding gage lines of the four rosettes were averaged and the average values used in the computations. The magnitudes and directions of the principal stresses and of the maximum shearing stress for each set of rosettes were computed.

\footnotetext{
${ }^{2}$ No material for test coupons was submitted with the specimen.
} 


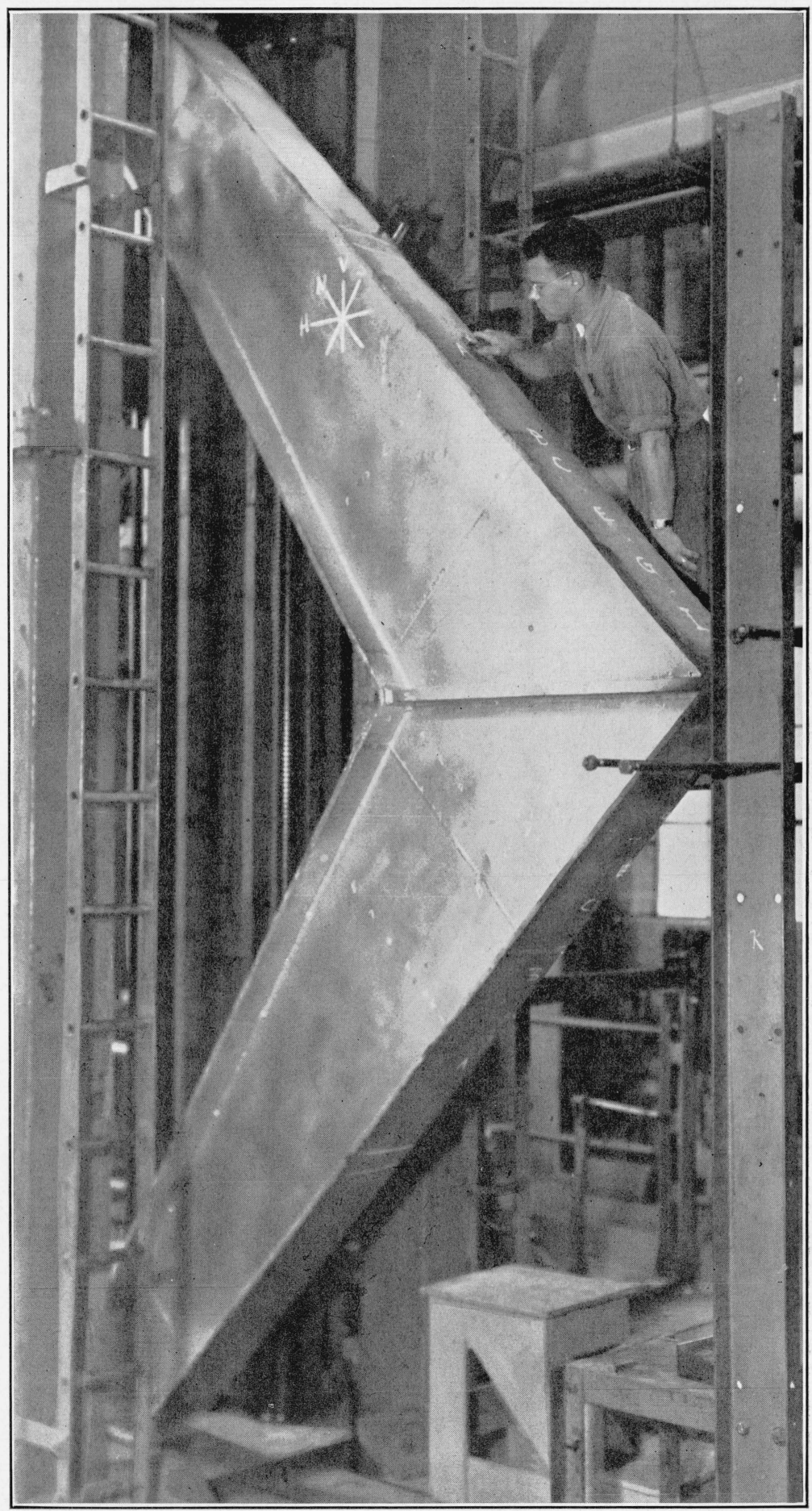

Figure 2.-Rigid-frame specimen in the testing machine. 


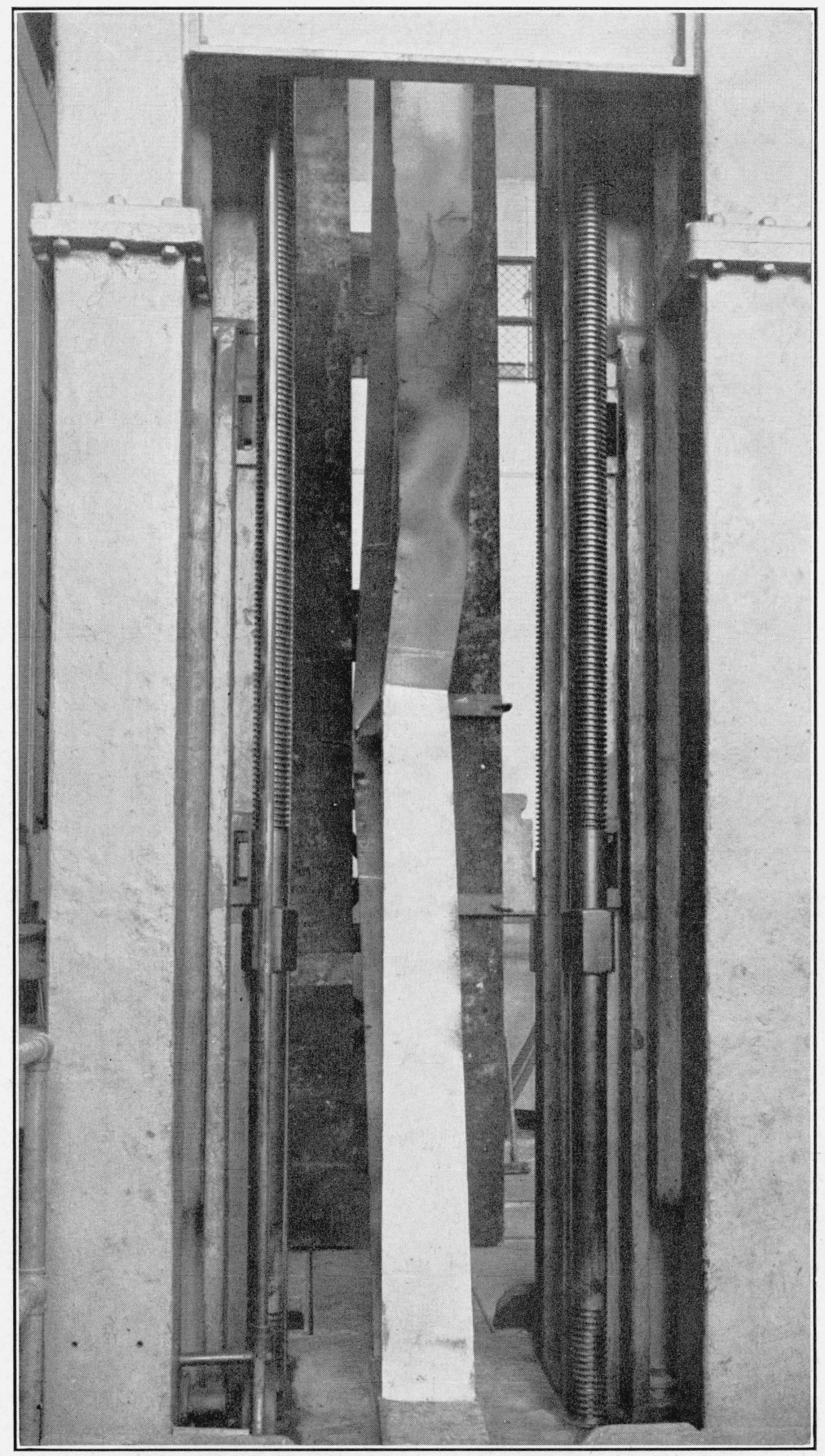

FIGURE 8.-Rigid-frame specimen after the maximum load of 153.6 kips had been passed. 


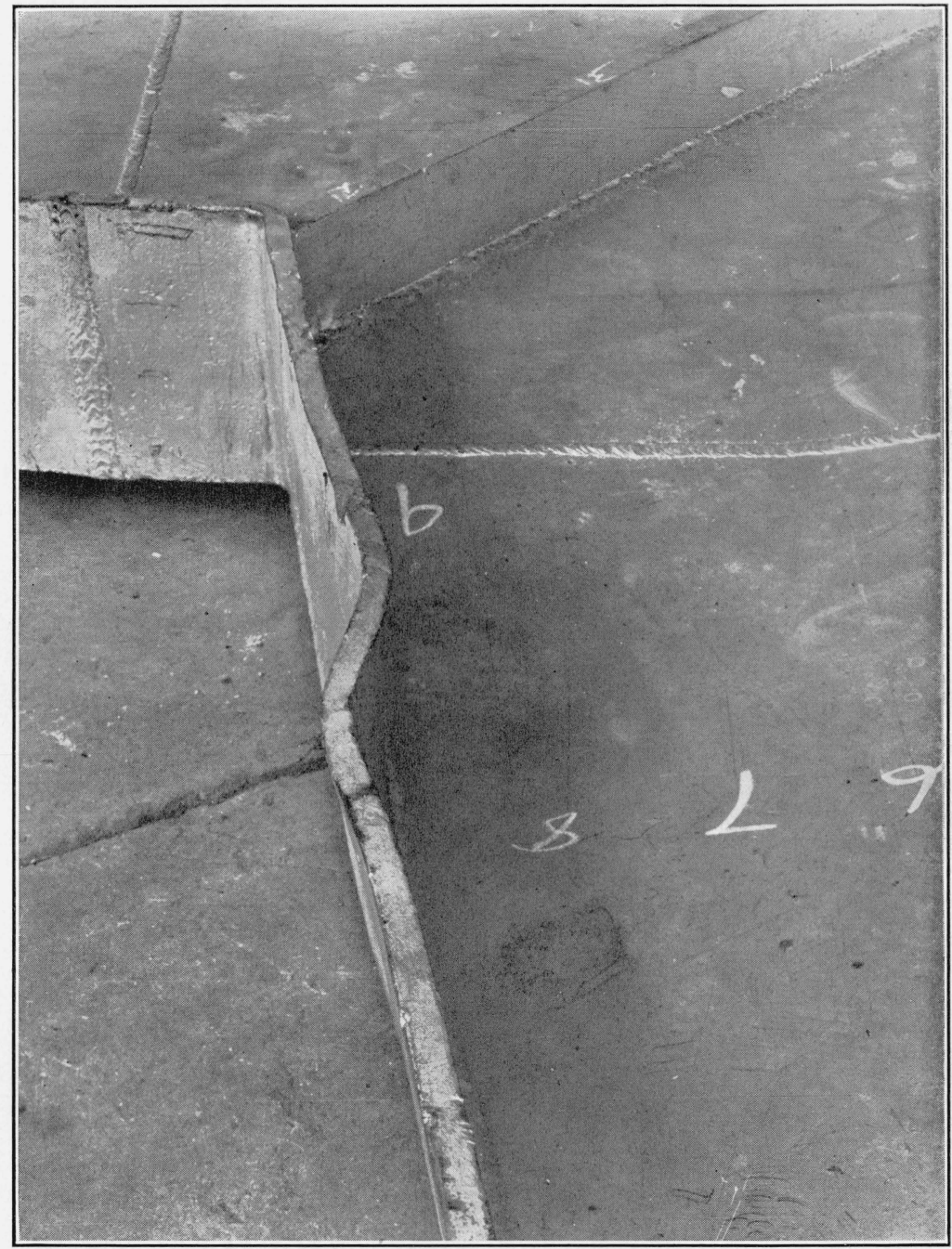

FIGURE 9.-Inner portion of the rigid-frame specimen after failure. 
The results of these computations are shown in figures 3 to 7 , inclusive. Figure 3 is a contour chart of the maximum principal stress. Each contour line is a locus of points of equal maximum principal stress in the plane of stress. The contour lines show only the magnitudes of the stress. The directions of the contour lines are not the directions of the maximum principal stresses. The contour lines do not give the values of the stresses in the diagonal stiffener. Similar contour charts of the minimum principal stress and of the maximum shearing stress are shown in figures 4 and 5 , respectively, except that the contour lines of maximum shearing stress in figure 5 were drawn for the three-dimensional state of stress. At any point at which the principal stresses in the plane of stress are of the same sign, the maximum shearing stress occurs in planes at $45^{\circ}$ to the plane of stress and is equal to one-half the numerically larger of these principal stresses.

The magnitudes and directions of the principal stresses in the plane of stress are shown in figure 6 . The normal and shearing stresses on sections perpendicular to the outer flanges are shown in figure 7 . The dotted lines in figure 7 show the bending stresses on the assumption that the direct compressive stress is uniform over the cross section.

The largest normal stresses occur at the inner corner of the frame, where the diagonal stiffener joins the inner flanges. The largest shearing stress occurs in this neighborhood also. These large stresses are local effects due to the action of the stiffener.

An analytical solution for the stresses in the knee was not obtained.

Because the load was applied to the flat end flanges of the specimen, the position of the load line is indefinite. If the flanges were initially parallel, the load line would pass through the center of the flanges at low loads. As the load increased, the load line would move toward the knee of the frame. The effective position of the load line may be computed as follows. On a cross section of a leg remote from the knee the normal-stress distribution is linear and presumably follows that of the ordinary beam theory. Assuming the direct compressive stress due to the normal component of the load to be distributed uniformly over the cross section, the moment arm of the load may be computed from the measured stresses. It was computed that for this test the effective load line moved about $7.4 \mathrm{in}$. from the center of the loading flanges toward the knee of the frame.

\section{MAXIMUM LOAD}

The rigid-frame specimen arranged for the determination of the maximum load is shown in figure 8 . The conditions for this test were the same as for the stress-distribution determination, except that the outer corner was restrained laterally.

The maximum load was 153.6 kips. Failure occurred by buckling of the web and flange on the compression side of the upper leg, as shown in figure 8. The buckle in the flange is shown more clearly in figure 9. The welds did not fail. Lüders' lines were not observed, as the mill scale had been removed from the specimen by the fabricators.

For the stress-distribution determination, the ratio of the load to the greatest measured stress was 2.91 kips per kip/in. ${ }^{2}$ Assuming a linear variation of stress with load up to failure, the greatest stress in the frame would be $52.8 \mathrm{kips} / \mathrm{in}^{2}{ }^{2}$ Since this is probably higher than the compressive yield point of the material, it is probable that the full compressive strength of the material was utilized. 


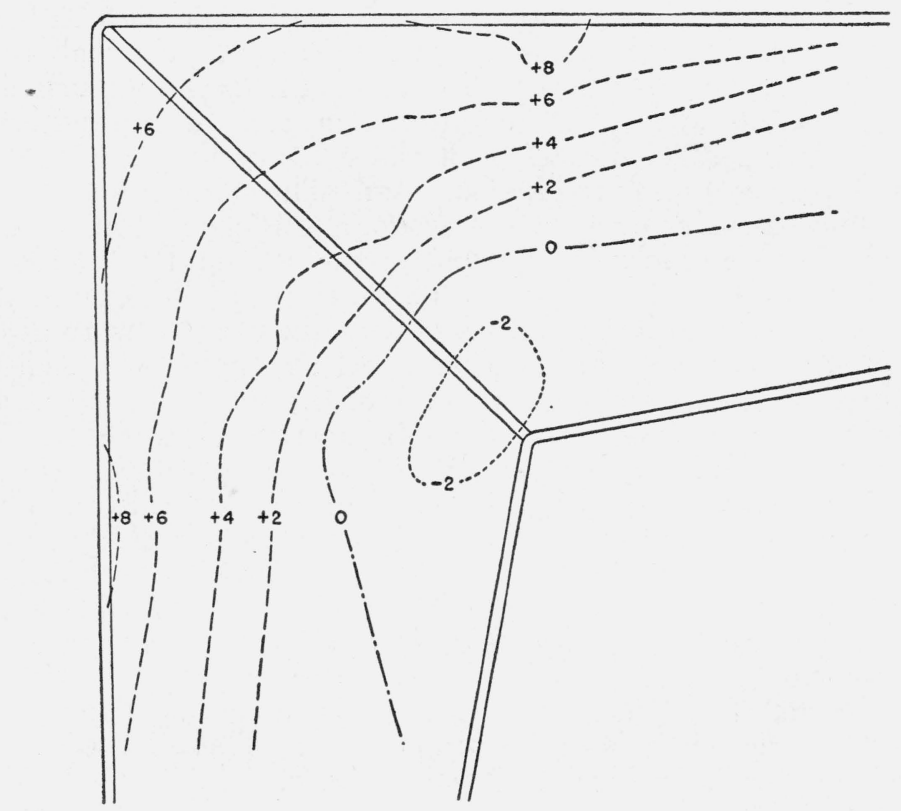

FIGURE 3.-Maximum principal stress, kips/in.2.

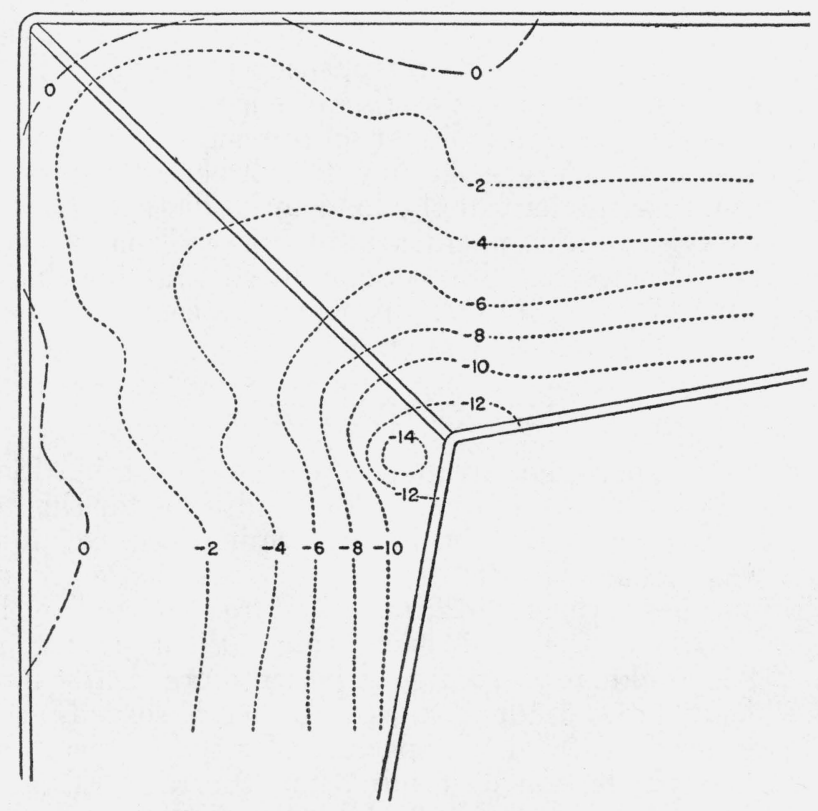

FIGURE 4.-Minimum principal stress, kips/in.2. 


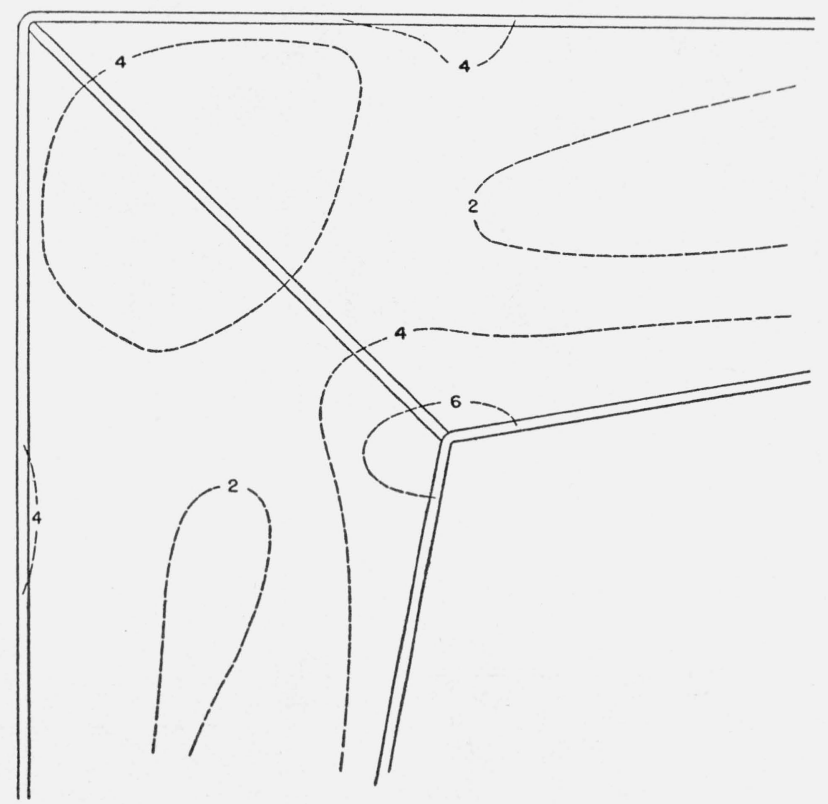

FigURE 5.-Maximum shearing stress, kips/in.2.

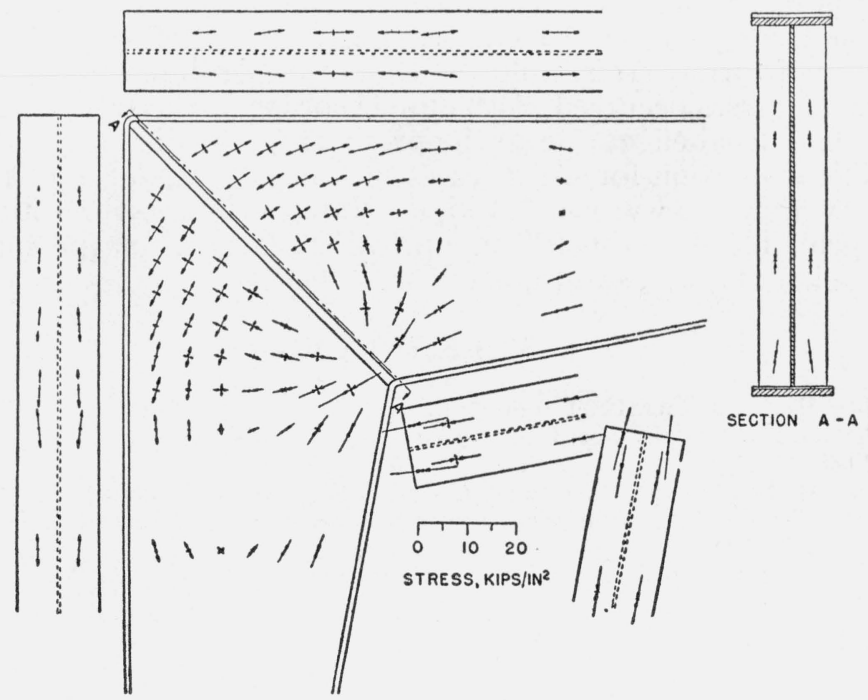

FIGURE 6.-Magnitude and direction of the maximum and of the minimum principal stresses. 


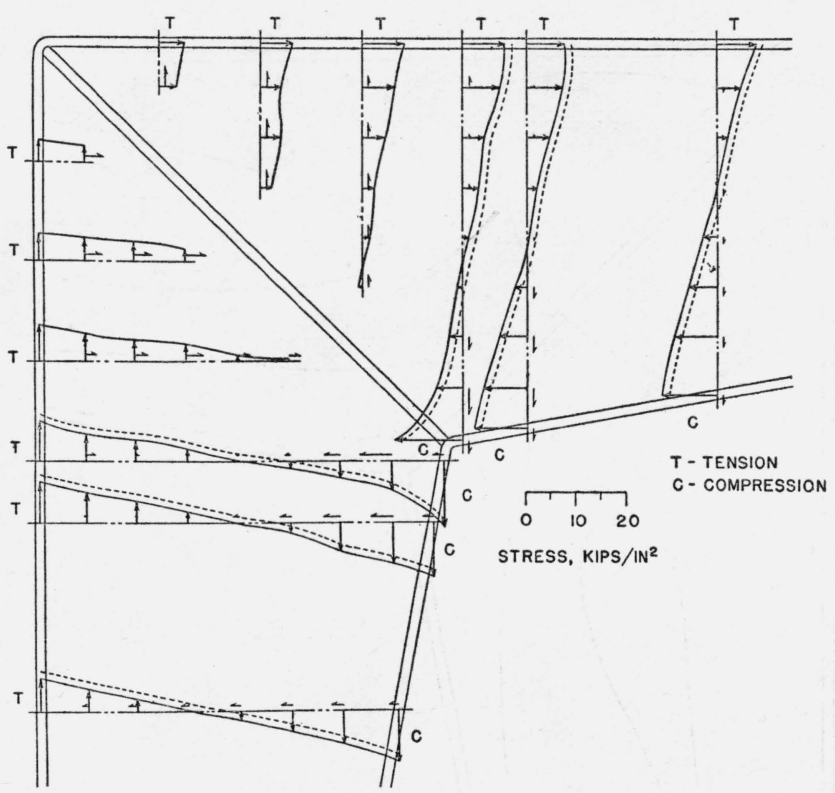

FigURE 7.-Normal and shearing stresses on twelve sections.

\section{SUMMARY}

The stress distribution in a welded steel rigid frame having straight flanges was determined experimentally. It was found that on cross sections of the legs remote from the inner corner of the frame, the distribution of normal stress followed that of the ordinary beam theory. The largest stresses occurred at the inner corner of the frame, and appeared to be a local effect due to the presence of the diagonal stiffener. No analytical solution for the stresses in the knee was obtained.

The maximum load was 153.6 kips. Failure occurred by buckling, but it is probable that the full compressive strength of the material was utilized. The welds did not fail.

\section{REFERENCES}

[1] Ambrose H. Stang, Martin Greenspan, and William R. Osgood, Strength of a riveted steel rigid frame having straight flanges, J. Research NBS \$1, 269 (1938) RP1130.

[2] Ambrose H. Stang, Martin Greenspan, and William R. Osgood, Strength of a riveted steel rigid frame having a curved inner flange, J. Research NBS $\mathbf{2 1}$, 853 (1938) RP1161.

[3] Welding Handbook, p. 7 (American Welding Society, New York, N. Y., 1938).

Washington, March 29, 1939. 